\title{
Correction to: Long-term psychosocial outcome following mild traumatic brain injury and minor stroke: a direct longitudinal comparison
}

\author{
Daan P. J. Verberne ${ }^{1,2}$ - Rudolf W. H. M. Ponds ${ }^{1,2,3,4} \cdot$ Mariëlle E. A. L. Kroese ${ }^{5} \cdot$ Melloney L. M. Wijenberg $^{2,6}$. \\ Dennis G. Barten ${ }^{7} \cdot$ Raphaël Pasmans ${ }^{8}$. Julie Staals ${ }^{9} \cdot$ Caroline M. van Heugten $^{1,2,6}$
}

Published online: 1 September 2021

(c) The Author(s) 2021

Correction to: Journal of Neurology (2021) 268:2132-2140
https://doi.org/10.1007/s00415-020-10385-6

The original version of this article unfortunately contained a mistake in Table 2. The corrected Table 2 is given in the following page.

The original article can be found online at https://doi.org/10.1007/ s00415-020-10385-6.

Caroline M. van Heugten

c.vanheugten@maastrichtuniversity.nl

1 Faculty of Health, Medicine and Life Sciences, School for Mental Health and Neuroscience (MHeNs), Maastricht University Medical Center, Maastricht University, P.O. 616 UNS 40, 6200 MD Maastricht, The Netherlands

2 Limburg Center for Brain Injury, Maastricht, The Netherlands

3 Department of Brain Injury Rehabilitation, Adelante Rehabilitation Centre of Expertise in Rehabilitation and Audiology, Hoensbroek, The Netherlands

4 Department of Medical Psychology, Maastricht University Medical Centre, Maastricht, The Netherlands
5 Department of Health Services Research, Faculty of Health, Medicine and Life Sciences, Maastricht University, Maastricht, The Netherlands

6 Department of Neuropsychology and Psychopharmacology, Faculty of Psychology and Neuroscience, Maastricht University, Maastricht, The Netherlands

7 Department of Emergency Medicine, VieCuri Medical Center, Venlo, The Netherlands

8 Department of Neurology, Zuyderland Medical Center, Heerlen, The Netherlands

9 Department of Neurology, Maastricht University Medical Center, Maastricht, The Netherlands 


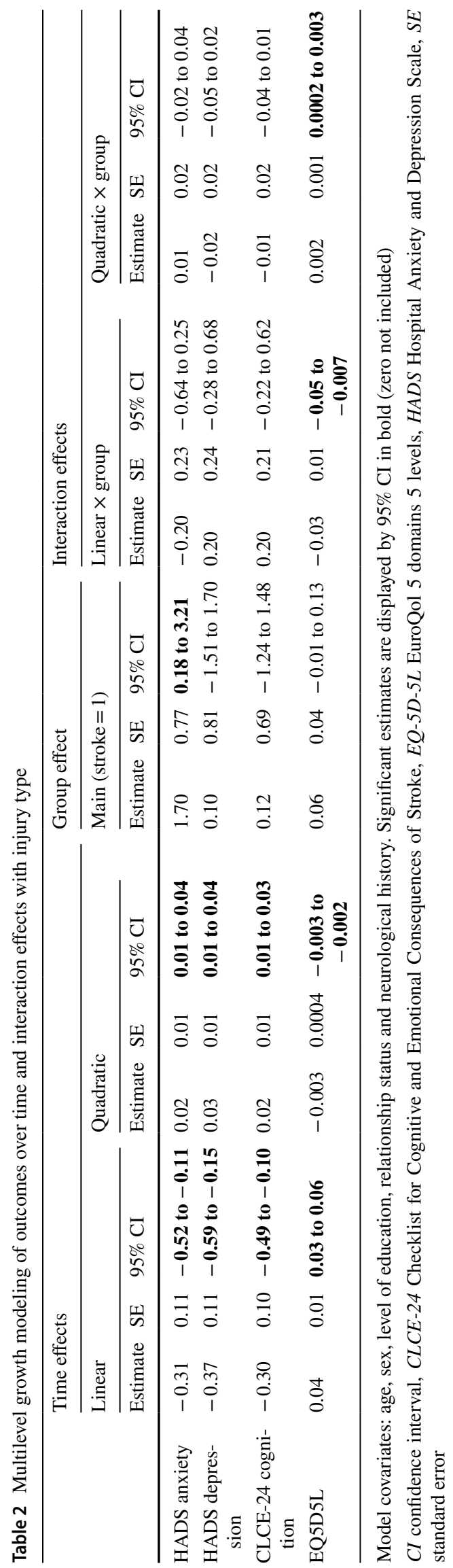

Open Access This article is licensed under a Creative Commons Attribution 4.0 International License, which permits use, sharing, adaptation, distribution and reproduction in any medium or format, as long as you give appropriate credit to the original author(s) and the source, provide a link to the Creative Commons licence, and indicate if changes were made. The images or other third party material in this article are included in the article's Creative Commons licence, unless indicated otherwise in a credit line to the material. If material is not included in the article's Creative Commons licence and your intended use is not permitted by statutory regulation or exceeds the permitted use, you will need to obtain permission directly from the copyright holder. To view a copy of this licence, visit http://creativecommons.org/licenses/by/4.0/. 